Artigos

Volume 9 - 2019| n. 20

\title{
Trabalho e Carreira Docente na Rede Municipal do Rio de Janeiro
}

\author{
Felipe Willian Ferreira de Alencar \\ Universidade Federal de São Paulo (UNIFESP), São Paulo/SP - Brasil
}

\section{Resumo}

Docentes da educação básica possuem grandes desafios no sentido de conquistar a valorização do magistério diante das políticas nacionais de carreira e financiamento da educação. Nesse sentido, investiga-se a carreira como um indicador das condições de trabalho dos professores da Rede Municipal do Rio de Janeiro, que realizaram uma greve em 2013 por melhores condições de carreira. Assim, a proposta neste artigo é comparar dois planos de carreira: o vigente à época da greve e o que foi aprovado no decurso da mobilização. Foram analisados os critérios de ingresso, a jornada de trabalho, as formas de movimentação na carreira e a composição da remuneração. Verificou-se que o concurso público foi o principal processo de contratação; houve criação de mais itens da remuneração; mudanças que conferiram criação de jornada única de 40 horas semanais e ampliação da movimentação na carreira, restritas a critérios orçamentários, de modo que esses elementos não foram estabelecidos como direitos dos docentes.

Palavras-chave: Carreira e Remuneração Docente. Valorização do Magistério. Condições de Trabalho Docente. Professores Municipais do Rio de Janeiro.

\section{Teachers' Work and Career in the Public Municipal Education System of Rio de Janeiro}

\begin{abstract}
Abtract
Teachers of K-12 education have great challenges in order to gain the valuation of teaching profession in the face of national career policies and education financing. The career is investigated as an indicator of the working conditions of the teachers of the educational public system of Rio de Janeiro, who held a strike in 2013 demanding for better conditions for their career. The proposal in this article is to compare two career plans: one current at the time of the strike and other which was approved during the mobilization. It was analyzed the following elements: admission criteria, working hours, career movement and compensation components. In the comparative analysis, it can be seen that the admission to the career was maintained by public tender; there were changes that fostered the creation of a 40-hour workweek; and there was an expansion of the career progression through the academic pathway. These were restricted to budgetary criteria, so that these elements are not established as teachers' rights.
\end{abstract}

Keywords: Teaching Career and Remuneration. Valuation of the Teaching Profession. Teaching Work Conditions. Teachers of Public Educational System of Rio de Janeiro. 
Trabalho e Carreira Docente na Rede Municipal do Rio de Janeiro

As ${ }^{1}$ reformas educacionais ao longo das décadas de 1990 e de 2000 tiveram como principal eixo a educação para a equidade social, passando a ser imperativo dos sistemas escolares a formação dos educandos para a empregabilidade. Nesse contexto, foram estabelecidas medidas de reorganização das redes de ensino nos seus aspectos físicos e administrativos, de modo a atender a expansão da cobertura escolar, que tendiam à padronização de importantes processos, tais como o livro didático, propostas curriculares centralizadas, avaliações externas, entre outras (OLIVEIRA, 2010), interferindo no trabalho dos profissionais da educação, a começar pelas questões concernentes ao processo de trabalho na escola e aos procedimentos normativos que determinam a carreira e a remuneração docente.

Políticas de financiamento da educação, como o Fundo de Manutenção e Desenvolvimento do Ensino Fundamental e Valorização do Magistério (Fundef) e o Fundo de Manutenção e Desenvolvimento da Educação Básica e Valorização dos Profissionais da Educação (Fundeb), demonstram a afirmação desse projeto. Tais políticas redistribuem parte dos recursos de estados e municípios, com complementação da União, destinando percentuais desses recursos para pagamento de profissionais do magistério, baseando sua aplicação a critérios de número e tipo de matrículas na educação básica e estabelecem que os entes federados criem planos de carreira dos professores de suas respectivas redes de ensino (BRASIL, 1996a; 2007). Com isso, faz-se pertinente considerar a carreira como um indicador das condições de trabalho do magistério.

Ainda que a questão do financiamento da educação e a remuneração docente estivessem centralmente colocadas na legislação, alguns autores fizeram ressalvas sobre a natureza e o formato do Fundef, e sobre a pertinência dessa política de financiamento da educação na criação de um padrão mínimo de qualidade nunca definido (ARELARO, 2007; DAVIES, 2008). Nem sempre o Fundef implicou uma melhoria da remuneração docente, visto que em muitos estados e municípios o que aconteceu foi a criação de algumas gratificações, sem mudança efetiva no vencimento-base ou mudança de nomenclatura de itens que já compunham a remuneração (ARELARO, 2007; DAVIES, 2008). Além disso, o prazo estabelecido para a criação de planos de carreira não foi necessariamente cumprido (CAMARGO; JACOMINI, 2011) e não houve a criação de um piso salarial nacional para os professores.

Davies (2008) analisou o Fundeb como um mecanismo de traços neoliberais, por essa política propor somente uma redistribuição de uma parte dos recursos já vinculados constitucionalmente à educação, mas em função da quantidade de matrículas das redes de ensino e com pouco acréscimo de recursos novos em relação à composição do Fundef. Para ele, o Fundeb "[...] é apenas mais uma proposta de racionalização dos gastos públicos segundo uma lógica quantitativista e se baseia no pressuposto de que os recursos são suficientes porém mal distribuídos entre os governos" (DAVIES, 2008, p. 9).

Apesar de a Lei do Fundeb ter estabelecido agosto de 2007 como prazo para a criação de Lei que determinaria o Piso Salarial Profissional Nacional (PSPN) para os profissionais da

1 Este artigo é parte da pesquisa nacional Remuneração de professores de escolas públicas da educação básica no contexto do Fundeb e do PSPN. A pesquisa teve vigência entre 2012 a 2016 e contou com financiamento da Coordenação de Aperfeiçoamento de Pessoal de Nível Superior (Capes), no âmbito do Observatório da Educação. 
Trabalho e Carreira Docente na Rede Municipal do Rio de Janeiro

educação, a instituição do PSPN ocorreu somente em $2008^{2}$ (BRASIL, 2008). Algumas questões permaneceram não contempladas para a valorização de profissionais da educação, para além dos professores. Pois, naquele contexto, apesar de o valor estabelecido ser um pouco maior do que a proposta inicial ( $R \$ 950,00)$, o piso continua não contemplando os demais trabalhadores em educação (CAMARGO et al., 2009).

No sentido de que as políticas educacionais nesse contexto possuem ligação com as condições de trabalho nas escolas públicas e com a remuneração dos profissionais da educação, o debate colocado seria sobre a necessidade de mais recursos públicos para o financiamento da educação pública.

Ao discutirem sobre a remuneração do trabalho docente e o financiamento da educação, principalmente sobre a discussão de que haveria maior necessidade de se destinar percentual maior do Produto Interno Bruto (PIB) nacional para o setor, Gatti, Barreto e André (2011, p. 140) ressaltam que não será possível cumprir as metas do Plano Nacional de Educação $(\mathrm{PNE})^{3}$ 2014-2020 com investimento atual um pouco menor do que 5\% do PIB: "[...] não teremos condições de alavancar uma trajetória diferente na educação escolar, principalmente no que se refere à melhor qualificação da formação de professores e à sua carreira". Contudo, a carreira docente indica um caminho distante da especificidade deste trabalho:

\begin{abstract}
Os planos de carreira e remuneração do magistério dos municípios dirigem-se mais para qualificar o quadro do magistério no grupo dos servidores públicos, definir níveis ou classes de progressão formais e adequar-se a leis federais na sua sequência. A maioria mostra-se como instrumento de natureza mais burocrática, não se fundamentando em perspectivas educacionais [...] (GATTI; BARRETO; ANDRÉ, 2011, p. 172).
\end{abstract}

Estudos regionalizados expressam a particularidade do atendimento em estados e municípios às normas nacionais, revelando os critérios de ingresso, a jornada de trabalho, as formas de movimentação na carreira e composição da remuneração. Aspectos que implicam na qualidade do trabalho no cotidiano escolar, referindo-se à formação do professor, ao tempo dedicado aos alunos, preparo de aulas, de avaliação e reuniões coletivas. Mas há, também, elementos em que avaliações externas e de desempenho tornam-se incrementos na construção do plano de carreira, movimentações na carreira que se tornam praticamente impossíveis de serem atingidas, como no caso do estado do Paraná, no qual a progressão na carreira até o topo perdura 70 anos (MINHOTO; GIGLIO, 2012; SOUZA et al., 2012; ARELARO et al., 2014).

Foi nesse contexto que foi realizada esta pesquisa, que analisou as reivindicações por carreira numa greve dos trabalhadores da educação do Rio de Janeiro, ocorrida entre agosto e outubro de 2013.

Essa greve se deu num cenário de lutas sociais ocorridas no Brasil em 2013, denominado de "Jornadas de Junho", que tiveram como estopim manifestações contra o aumento das tarifas do transporte público coletivo, que revogaram o reajuste em mais de cem cidades, e com prosseguimento das manifestações, dirigidas inicialmente pelo Movimento Passe Livre e por movimentos que se formavam de acordo com o próprio ritmo coletivo das ações de rua (ROLNIK, 2013; SECCO, 2013).

2 O PSPN foi estabelecido com a aprovação da Lei no $11.738 / 2008$ (BRASIL, 2008).

3 O texto das autoras citadas foi publicado em 2011, mas a aprovação do PNE ocorreu apenas em 2014. 
Trabalho e Carreira Docente na Rede Municipal do Rio de Janeiro

O movimento social organizado em sindicatos, coletivos e movimentos populares convocou uma greve geral para o dia 11 de julho do referido ano. Antecedidos por esses acontecimentos, os professores da Rede Municipal do Rio de Janeiro iniciaram greve por tempo indeterminado, convocada pelo Sindicato Estadual dos Profissionais de Educação do Rio de Janeiro (Sepe), reivindicando reajuste salarial de 19\%, plano de carreira unificado, 1/3 da carga horária para planejamento, fim da meritocracia e melhores condições de trabalho (SEPE, 2013a).

A demanda por carreira obteve um tratamento mais efetivo após realização de uma manifestação no dia 20 de agosto de 2013, que contou com a participação de 20 mil manifestantes. Na data, uma comissão do Sepe foi recebida pela prefeitura do Rio de Janeiro, ao final, demarcando a reabertura de negociações (SEPE, 2013b).

No entanto, a despeito da reabertura de negociação, a prefeitura do Rio de Janeiro enviou, em caráter de emergência, à Câmara municipal da cidade, o Projeto de Lei (PL) 442, que continha o Plano de Cargos, Carreira e Remuneração (PCCR). Com a rejeição dos professores à proposta de PCCR elaborada pela prefeitura, enviado à Câmara municipal em caráter de urgência, os servidores decidiram realizar manifestações no plenário da Câmara municipal em 27 de setembro de 2013, culminando na ocupação do prédio por 48 horas. No dia 1 de outubro, dia da sessão que aprovou o atual PCCR (Lei $n^{\circ}$ 5623/2013), os trabalhadores da educação municipal e apoiadores realizaram uma manifestação que foi fortemente reprimida pela Polícia Militar (PM) do estado do Rio de Janeiro ${ }^{4}$ (SEPE, 2013c).

Este artigo, primeiramente, dedicar-se-á a descrever aspectos do contexto da Rede Municipal de Ensino do Rio de Janeiro, no ano de 2013. Realizar-se-á uma dimensão quantitativa de matrículas, escolas, turmas, cargos e jornadas de trabalho dos docentes a partir de dados obtidos junto ao Instituto Brasileiro de Geografia e Estatística (IBGE), ao Censo Escolar e à Prefeitura do Rio de Janeiro ${ }^{5}$.

Em um segundo momento, pretende-se discutir sobre a política de carreira dos professores municipais do Rio de Janeiro, por meio de uma descrição e análise comparativa a partir da Lei municipal $n^{\circ}$ 2391, de 8 de dezembro de 1995 (RIO DE JANEIRO, 1995) e alterações posteriores ${ }^{6}$, que continha o plano de carreira vigente durante o período da greve, em 2013, e da Lei municipal $n^{\circ}$ 5623, de 1 de outubro de 2013 (RIO DE JANEIRO, 2013a), PCCR de professores do município do Rio de Janeiro, sancionada pelo ex-prefeito Eduardo Paes (filiado ao Partido do Movimento Democrático Brasileiro - PMDB) em função da greve no mesmo ano.

4 Sobre as reivindicações da greve de professores da rede municipal do Rio de Janeiro de 2013, consultar Alencar (2018).

5 As informações sobre quantidade de escolas, turmas, professores foram obtidas em documento elaborado pela Prefeitura do Rio de Janeiro (2013b). Disponível em: <http://www.rio.rj.gov.br/dlstatic/10112/ 126674/4108733/EducacaoRio_vf.pdf>. Acesso em: 15 fev. 2015.

6 O PCCR contido na Lei $n^{\circ} 2391 / 1995$ obteve reformulações posteriores em alguns aspectos, presentes na Lei municipal $n^{\circ} 4.814 / 2008$ (RIO DE JANEIRO, 2008). 
Trabalho e Carreira Docente na Rede Municipal do Rio de Janeiro

\section{Breve contextualização sobre a Rede Municipal de Ensino do Rio de Janeiro}

Segundo o Censo Escolar, a Rede Municipal de ensino da cidade do Rio de Janeiro atendia o total de 671.670 matrículas em 2013 e, de acordo com a Secretaria Municipal de Educação, a rede possuía 22.482 turmas. Dessas matrículas e turmas, a quantidade mais expressiva concentrava-se no Ensino Fundamental (EF), abrangendo 512.691 matrículas, $76 \%$ do total da rede, e 15.542 turmas, seguido pelo atendimento na Educação Infantil (EI), com 121.882 matrículas, 18\%, e 5.180 turmas, na Educação de Jovens e Adultos (EJA) havia 25.489 matrículas, 4\%, e 1.045 turmas, e, por fim, a Educação Especial possuía 11.608 matrículas, $2 \%$, e 715 turmas.

Em relação ao atendimento no ensino fundamental, a rede estadual abrangia apenas $1 \%$, a rede privada $33 \%$, ao passo que a rede municipal atendia $65 \%$. Esse dado denota uma marca de municipalização do EF na cidade do Rio de Janeiro, com expressiva entrada da iniciativa privada.

A rede pública de educação básica totalizava 922.968 matrículas nas redes federal, estadual e municipal na cidade do Rio de Janeiro, abrangendo $97 \%$ de atendimento; na rede privada eram 492.811 matrículas, 3\%. A despeito do expressivo atendimento no EF na rede municipal carioca, a rede de ensino privada concentrava a segunda maior quantidade de matrículas no município, em 2013, possuindo a cobertura de $35 \%$ de atendimento de matrículas, ao passo que na educação infantil a rede privada possuía 6.002 matrículas a menos que a rede municipal, e superava as redes municipal, estadual e federal no atendimento ao Ensino Técnico.

Quadro 1 - Matrículas na educação básica no município do Rio de Janeiro (2013)

\begin{tabular}{|c|c|c|c|c|c|c|c|}
\hline \multicolumn{2}{|c|}{ Tipo de rede } & $\begin{array}{c}\text { Educação } \\
\text { Infantil }\end{array}$ & $\begin{array}{c}\text { Ens. } \\
\text { Fund. }\end{array}$ & $\begin{array}{c}\text { Ens. } \\
\text { Médio }\end{array}$ & $\begin{array}{c}\text { Ens. } \\
\text { Técnico }\end{array}$ & EJA & Total \\
\hline \multirow{3}{*}{ Federal } & Matrículas & 619 & 10082 & 8271 & 3995 & 643 & 24575 \\
\cline { 2 - 8 } & Turmas & 63 & 444 & 299 & 196 & 37 & 1039 \\
\hline \multirow{2}{*}{ Estadual } & Matrículas & 298 & 9606 & 164756 & 9902 & 41243 & 226723 \\
\cline { 2 - 9 } & Turmas & 24 & 393 & 5130 & 456 & 953 & 6956 \\
\hline \multirow{3}{*}{ Municipal } & Matrículas & 121882 & 512691 & 0 & 0 & 25489 & 671670 \\
\cline { 2 - 8 } & Turmas & 5233 & 16566 & 0 & 0 & 1064 & 22863 \\
\hline \multirow{2}{*}{ Privada } & Matrículas & 115880 & 259738 & 65314 & 37599 & 12292 & 492811 \\
\cline { 2 - 8 } & Turmas & 9151 & 13504 & 2353 & 2282 & 756 & 28046 \\
\hline
\end{tabular}

Fonte: Censo Escolar.

A Rede Municipal de Ensino do Rio de Janeiro possuía, em 2013, o total de 1.367 unidades escolares, divididas em 864 escolas de EF, das unidades de EI, 246 creches e 151 Espaços de Desenvolvimento Infantil (EDI), 95 Centros Integrados de Educação Pública (Ciep), 10 Escolas Especiais e 1 Centro Municipal de Referência de Educação de Jovens e Adultos (CMREJA). 
Trabalho e Carreira Docente na Rede Municipal do Rio de Janeiro

\section{Gráfico 1 - Unidades escolares da Rede Municipal de Ensino do Rio de Janeiro (2013)}

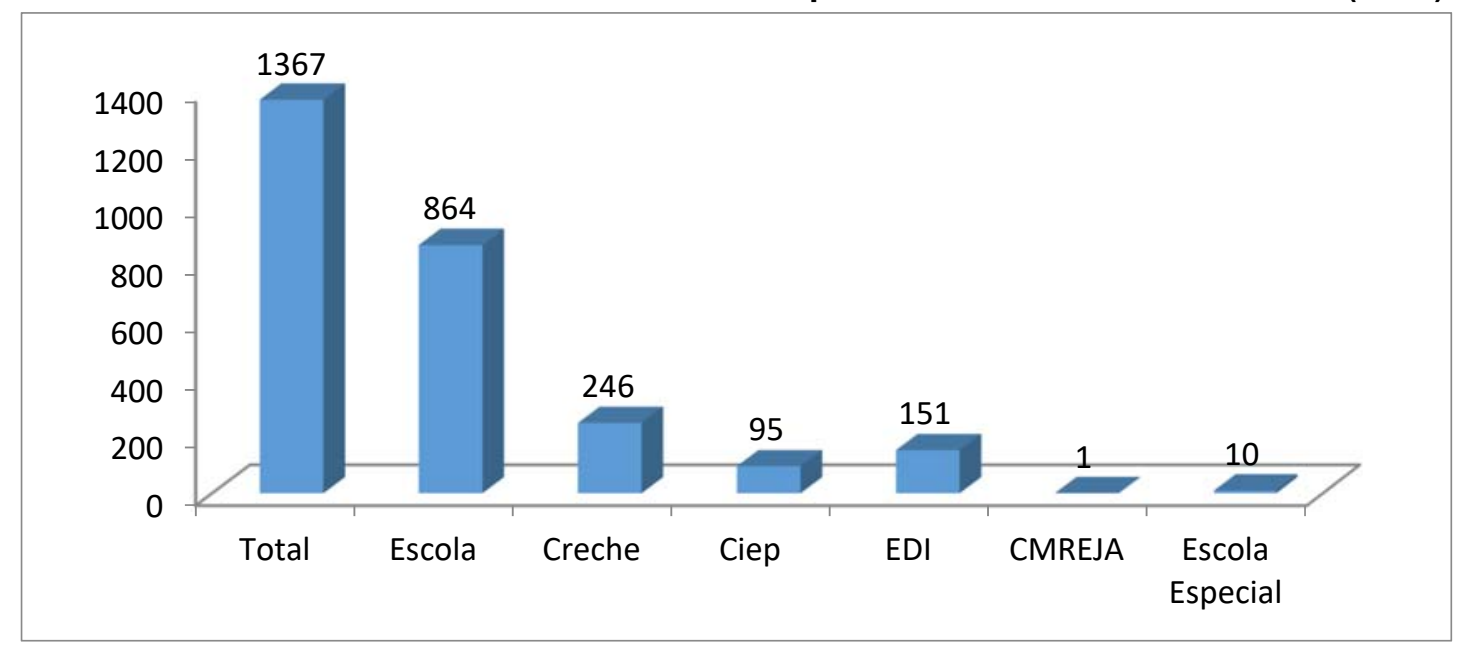

Fonte: Secretaria Municipal de Educação do Rio de Janeiro.

No tocante aos trabalhadores da educação, a Rede de ensino carioca contava com 42.903 Professores e 17.315 Profissionais de Apoio, segundo dados da Prefeitura do Rio de Janeiro. A composição de cargos do quadro de pessoal do magistério, no ano de 2013, as respectivas etapas e modalidades de ensino com as quais os docentes trabalham estão sintetizadas no Quadro 2:

Quadro 2 - Cargo, qualificação e área de atuação do quadro de magistério municipal do Rio de Janeiro

\begin{tabular}{|c|c|c|}
\hline Cargo & Qualificação & Área de atuação \\
\hline Professor de Educação Especial & Habilitação específica em nível superior & Educação Especial \\
\hline Professor II & $\begin{array}{c}\text { Habilitação em magistério de nível médio, } \\
\text { Licenciatura curta, Licenciatura plena }\end{array}$ & $\begin{array}{c}\text { Educação infantil e } 1^{\circ} \text { ao } 5^{\circ} \text { ano } \\
\text { do ciclo } 1 \text { do Ensino Fundamental }\end{array}$ \\
\hline Professor I & Licenciatura plena & $\begin{array}{c}6^{\circ} \text { ao } 9^{\circ} \text { ano do ciclo } 2 \text { do Ensino } \\
\text { Fundamental }\end{array}$ \\
\hline Especialista de Educação & $\begin{array}{c}\text { Habilitação em Orientação Educacional, } \\
\text { Supervisão Escolar, Administração Escolar }\end{array}$ & $\begin{array}{c}\text { Educação Infantil, } 1^{\circ} \text { ao } 5^{\circ} \text { ano do } \\
\text { ciclo } 1 \text { e } 6^{\circ} \text { ao } 9^{\circ} \text { ano do ciclo } 2 \text { do } \\
\text { Ensino Fundamental }\end{array}$ \\
\hline
\end{tabular}

Fonte: Rio de Janeiro (1995).

A Rede municipal de ensino possuía uma diversidade de cargos de professores dividida entre 18.418 ocupantes do cargo de Professor I, 21.632 no cargo de Professor II e 2.853 no cargo de Professor de Educação Infantil/Educação Especial. Após a greve de 2013, houve a criação dos cargos de Professor de Educação Infantil (PEI) e Professor de Ensino Fundamental (PEF), contemplados no PCCR aprovado no referido ano.

As jornadas de trabalho apresentavam a seguinte conformação: 16 horas semanais, 22 horas e 30 minutos semanais, 30 horas semanais e 40 horas semanais. No entanto, apesar dessa variedade de jornadas de trabalho, uma parcela significativa ocupava as jornadas parciais de trabalho, sendo $53 \%$ de professores em jornada de 22 horas e 30 minutos semanais, $40 \%$ em jornada de 16 horas semanais e apenas $6 \%$ em jornada de 40 horas semanais, além de $1 \%$ em jornada de 30 horas semanais, como ilustrado no gráfico a seguir. Com o PCCR aprovado em 2013, houve um incentivo para inserir mais docentes em jornadas 
Trabalho e Carreira Docente na Rede Municipal do Rio de Janeiro

de 40 horas semanais, uma perspectiva de jornada única. No entanto, vigora ainda a diversidade de jornadas de trabalho.

Gráfico 2 - Docentes por jornada de trabalho (2013)

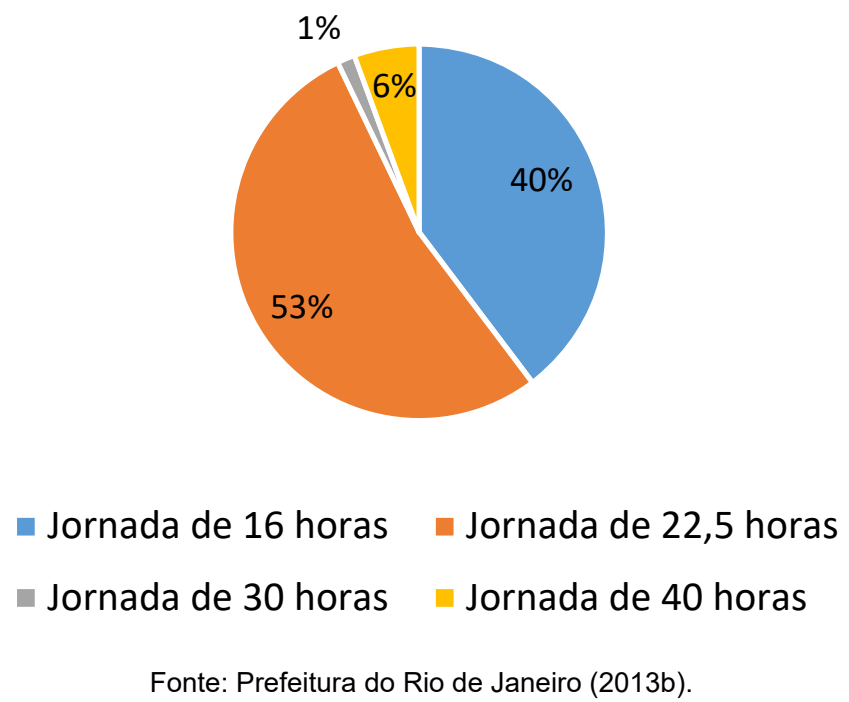

Ao observarmos o número de professores, considerando sua formação e jornada de trabalho, maiores quantidades concentram-se no cargo Professor I (que trabalha com ciclo 2 do EF), com licenciatura plena, na jornada de 16 horas semanais, contando com 17.037 professores, seguido do cargo de Professor II (que trabalha com El e ciclo 1 do EF), com licenciatura plena, em jornada de 22 horas e 30 minutos semanais, com 12.444 professores e cargo de Professor II, formação em nível médio, com 6.488 professores em jornada de 22 horas e 30 minutos semanais.

Gráfico 3 - Docentes por cargo e jornada de trabalho (2013)

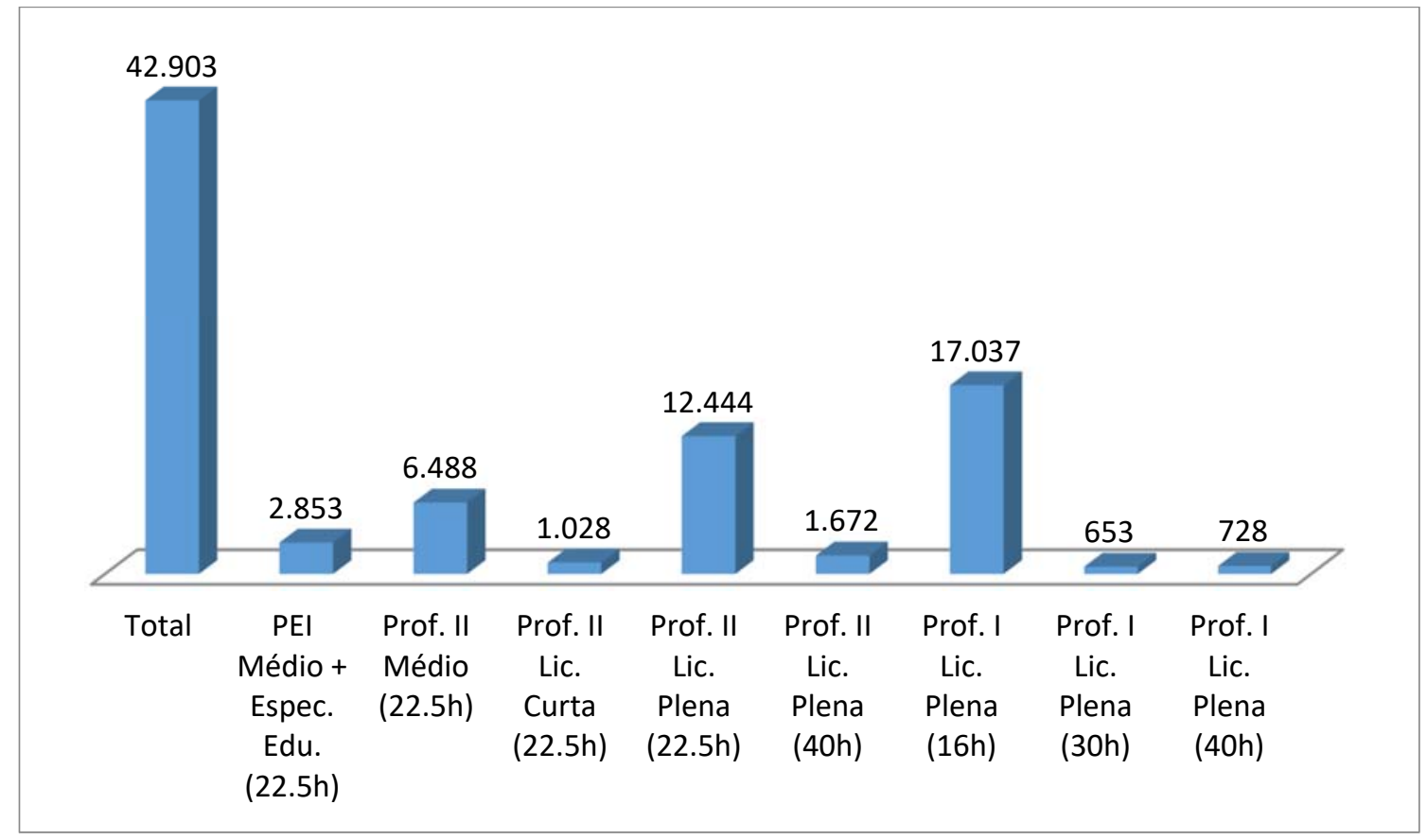

Fonte: Prefeitura do Rio de Janeiro. 
Trabalho e Carreira Docente na Rede Municipal do Rio de Janeiro

Fazendo uma leitura desses dados sobre as condições de trabalho de professores cariocas, pode-se chegar à conclusão de que a maioria dos professores deve possuir dupla ou tripla jornada de trabalho, na rede municipal ou em outras redes de ensino (públicas e/ou privadas) para complementação salarial, pelo fato de a maioria ocupar as jornadas parciais de trabalho. Além disso, professores sem formação em nível superior cobriam uma parcela importante do atendimento na educação infantil e no primeiro ciclo do ensino fundamental, e compõem esse quadro, que exige dedicação em mais de uma escola ou rede, tornando-se um elemento para discutir a qualidade do ensino na cidade.

\section{Carreira docente no município do Rio de Janeiro}

\section{Ingresso na carreira docente}

As políticas educacionais e as políticas de regulamentação da carreira docente, desde a Constituição de 1934, têm estabelecido que o ingresso na carreira de professores no Brasil deve ocorrer, obrigatoriamente, mediante a realização de concurso público de provas e títulos (CAMARGO; JACOMINI, 2011). Na Constituição Federal de 1988, essa medida parte da prerrogativa de que essa forma de ingresso garantiria uma melhora na qualidade do ensino público.

No Quadro 3 estão sintetizadas algumas definições para o ingresso na carreira que corroboram com as exigências nacionais, segundo a Resolução CNE/CEB n 02/2009 (BRASIL, 2009), e as leis municipais do Rio de Janeiro, que estabeleceram o PCCR em análise.

Quadro 3 - Definições para ingresso na carreira: Brasil e Rio de Janeiro

\begin{tabular}{|c|c|c|}
\hline Resolução CNE/CEB nº 02/2009 & Lei $n^{\circ}$ 2391/1995 & Lei $n^{\circ} 5623 / 2013$ \\
\hline $\begin{array}{l}\text { Art. } 4^{\circ} \text { As esferas da administração pública que } \\
\text { oferecem alguma etapa da Educação Básica, } \\
\text { em quaisquer de suas modalidades, devem } \\
\text { instituir planos de carreira para todos os seus } \\
\text { profissionais do magistério, e, eventualmente, } \\
\text { aos demais profissionais da educação, } \\
\text { conforme disposto no } \S 2^{\circ} \text { do artigo } 2^{\circ} \text { desta } \\
\text { Resolução, dentro dos seguintes princípios: } \\
\text { [...] II - acesso à carreira por concurso público } \\
\text { de provas e títulos e orientado para assegurar a } \\
\text { qualidade da ação educativa; }\end{array}$ & $\begin{array}{l}\text { Art. } 5^{\circ} \mathrm{O} \text { ingresso em qualquer das } \\
\text { carreiras previstas nesta Lei será } \\
\text { feito exclusivamente através de } \\
\text { concurso público de provas, } \\
\text { posicionando-se o servidor na } \\
\text { referência inicial da classe em que } \\
\text { concorreu como candidato. }\end{array}$ & $\begin{array}{l}\text { Art. } 3^{\circ} \mathrm{O} \text { ingresso no Quadro de } \\
\text { Pessoal da SME dar-se-á mediante } \\
\text { a nomeação para cargo de } \\
\text { provimento efetivo, submetido ao } \\
\text { regime estatutário, mediante prévia } \\
\text { aprovação em concurso público, } \\
\text { obedecidos a ordem de classificação } \\
\text { e o prazo de sua validade. }\end{array}$ \\
\hline
\end{tabular}

Fonte: Brasil (2009); Rio de Janeiro (1995; 2013a; 2013b).

Segundo a Lei Municipal $n^{\circ} 2391 / 1995$, o ingresso na carreira docente ocorre por meio de concurso público de provas e títulos, para compor o quadro permanente, de provimento efetivo e o quadro suplementar, em vacância. A carreira abrange o grupo do magistério, classificado pelos cargos de Professor II, Professor I, Supervisor Pedagógico e Orientador educacional.

$\mathrm{Na}$ Lei Municipal $n^{\circ} 5623 / 2013$, o ingresso na carreira docente é estabelecido por diferentes etapas, ocorrendo primeiramente 1. via concurso público de provas, com uma prova de caráter eliminatório e classificatório; 2 . uma avaliação prática de didática; 3 . um curso de formação ofertado pela Rede, ambos de caráter eliminatório e 4. uma prova de títulos, de caráter classificatório. 
Trabalho e Carreira Docente na Rede Municipal do Rio de Janeiro

A carreira é direcionada para a seguinte classificação: Professor de Educação Infantil (PEI), Professor de Ensino Fundamental (PEF) - antigos Professor I, com jornada de 16, 30 e 40 horas semanais - e Professor II, com jornada de 40 horas semanais. São exigidas as titulações mínimas de nível médio completo, na modalidade Normal para PEl e graduação em licenciatura de nível superior para PEF.

O PCCR aprovado em 2013 possui mais elementos da avaliação para o ingresso, estabelecendo mais etapas eliminatórias e classificatórias que não somente a prova objetiva ou dissertativa, diferentemente do que era previsto no PCCR de 1995. Nos aspectos sobre os critérios de ingresso na carreira docente, presentes nos planos de carreira em análise (1995 e 2013) apresentados, ressalta-se a importância do concurso público para ingresso, pois, além de combater práticas clientelistas, há possibilidade de seleção de profissionais qualificados dentro dos critérios que o concurso público pode aferir e, também, a periodicidade estabelecida para a realização de concurso contribui para que a maioria dos professores seja efetiva e tenha garantia de direitos.

\section{Jornadas de trabalho}

A composição da jornada de trabalho dos professores consta entre os elementos fundamentais para a valorização do trabalho em educação, pelo fato de se ter avançado, nas políticas públicas, no reconhecimento de que o trabalho do professor não se restringe apenas à interação com estudantes em aula e que as demais atividades inerentes à função docente devem estar incluídas na jornada de trabalho.

A Lei de Diretrizes e Bases da Educação Nacional (Lei n 9394/1996 - LDB/1996) estabelece que deve haver período reservado a estudos, planejamento e avaliação, incluídos na carga de trabalho do professor. A Lei $n^{\circ} 11.738 / 2008$ estabelece que esteja previsto na composição da jornada de trabalho o limite máximo de $2 / 3$ da carga horária para o desempenho das atividades de interação com os educandos (BRASIL, 2008). Já a Resolução CNE/CEB no 2/2009 (BRASIL, 2009) recomenda que a jornada de trabalho seja preferencialmente em tempo integral de, no máximo, 40 horas semanais, havendo ampliação de parte da jornada que seja destinada às atividades de preparação de aulas, correção de produções dos alunos, reuniões escolares, contato com a comunidade e formação continuada.

Na Lei municipal n²391/1995 (RIO DE JANEIRO, 1995), havia quatro tipos de jornada de trabalho, ocupadas por cargos determinados da seguinte forma:

1. Professor II - 22 horas e 30 minutos semanais, 40 horas semanais; e

2. Professor I - 16 horas/aula semanais e 30 horas/aula semanais.

As jornadas possuíam a seguinte composição: 
Trabalho e Carreira Docente na Rede Municipal do Rio de Janeiro

Quadro 4 - Composição das jornadas de trabalho docente no Rio de Janeiro (Lei Municipal n 2391/1995)

\begin{tabular}{|c|c|c|}
\hline Jornada semanal & Regência de turma & Atividades complementares \\
\hline 16 horas/aula & 12 horas & 4 horas \\
\hline 22 horas e 30 minutos & 20 horas & 2 horas e 30 minutos \\
\hline 30 horas & 23 horas & 7 horas \\
\hline 40 horas & 30 horas & 10 horas \\
\hline \multicolumn{3}{|c}{ Fonte: Rio de Janeiro (1995). }
\end{tabular}

Um elemento relacionado à importância do estabelecimento de horas para a dedicação do professor não somente em interação com estudantes leva em consideração que proporcionar horário para capacitação é essencial para sua qualificação profissional. Contudo, na realidade social e educacional enfrentada cotidianamente pelos trabalhadores em educação e pelos alunos, somente a determinação de carga horária semanal distribuída em regência de classe, formação continuada e horas complementares não garante integração qualitativa do docente em demais trabalhos a serem realizados na unidade escolar, devido à sobrecarga de trabalho que porventura ele tem (GOUVEIA et al., 2006).

$\mathrm{Na}$ Lei municipal $n^{0} 5.623 / 2013$ já se estabelecia a tendência de criação de jornada única de trabalho de 8 horas diárias e 40 horas semanais. No entanto, isso ocorreria mediante decisão do Poder Executivo, desde que houvesse acordo com a necessidade de serviço, a implementação de critérios e disponibilidade orçamentária anual, como condição para a implantação da jornada de trabalho de 40 horas semanais.

A professores que ocupassem as jornadas de trabalho, segundo o PCCR de 1995, era garantido o respeito ao direito de opção de manutenção da jornada anterior ou adequar-se à nova para os cargos Professor I, jornada de 16 horas e de 30 horas semanais, Professor II, com jornada de trabalho de 22 horas e 30 minutos semanais, e PEI, com jornada de 22 horas e 30 minutos semanais.

A Lei municipal $n^{0} 5.623 / 2013$ estabelece que a implantação da jornada de trabalho, prevista na Lei Federal $n^{\circ} 11.738 / 2008$, seria realizada paulatinamente, seguindo orientações do planejamento, e condicionada à disponibilidade orçamentária e às orientações contidas no Parecer $n^{\circ}$ 18/2012 do CNE/CEB.

Dentre as orientações relacionadas à jornada de trabalho dos professores está presente a necessidade de considerar uma aplicação que não recaia sobre o aumento de duração do tempo da hora-aula, mas uma aplicação individual ao docente que cumpre a jornada de 40 horas semanais, estabelecendo que

[...] ao professor deve ser assegurada uma composição da jornada de trabalho que comporte, no máximo, 2/3 (dois terços) de cada unidade que compõe essa jornada, ou seja, cada hora de interação com os estudantes. E, em decorrência, no mínimo 1/3 (um terço) destas horas destinadas a atividades extraclasse. Assim, em uma jornada de 40 horas semanais, independentemente da unidade de tempo que as compõem para os estudantes (60 minutos, 50 minutos e 45 minutos) 26,66 destas serão destinadas à interação com educandos e as demais 13,33 para atividades extraclasse (BRASIL, 2012, p. 12).

Como já exposto neste artigo, o município do Rio de Janeiro possuía, no ano de 2013, a ampla maioria de docentes em jornadas de trabalho parciais. Um dado já explicitado na literatura sobre o trabalho docente, em que induzido pelos baixos salários e enquadrado em 
Trabalho e Carreira Docente na Rede Municipal do Rio de Janeiro

jornadas de trabalho parciais, o professor é obrigado a duplicar e até triplicar a sua jornada. Fato já presente no cotidiano educacional há seis décadas: "O professor-operário, no meio de uma avassaladora inclusão de milhões de matrículas nos sistemas escolares primário e secundário, de 1950 a 1980, dobrou e até triplicou sua jornada, por pressão da demanda e/ou necessidade de sobrevivência" (MONLEVADE, 2000, p. 63).

Embora haja, desde 2013, tendência a fomentar jornada integral de trabalho na rede municipal do Rio de Janeiro, permanece uma situação que condiciona a implementação dessa política mediante a disponibilidade orçamentária do município, o que possivelmente deve impor empecilhos ao professor que queira exercer a jornada integral como um direito.

\section{Formas de movimentação na carreira}

Nos planos de carreira de professores da rede municipal do Rio de Janeiro, em análise, há duas formas de movimentação na carreira: 1. progressão horizontal via titulação e 2. progressão vertical pelo tempo de serviço.

No PCCR anterior à greve de 2013 (Lei municipal $n^{\circ}$ 2391/1995), a movimentação na carreira pela via da titulação acadêmica guardava, entre os níveis, o percentual de $10 \%$, cumulativos no vencimento-base ${ }^{7}$, a partir do ponto em que o professor é enquadrado, denominado de classe. No PCCR aprovado em 2013 (Lei municipal n 5623/2013), essa característica de enquadramento em classes do professor segundo a sua formação se mantêm, mas criaram-se mais três faixas de critérios de carreira específicas para quem possui pós-graduação (enquadramento nas Classes A1, A2 e A3), apenas para os ocupantes do cargo de Professor de Ensino Fundamental (PEF). No entanto, a movimentação dar-se-á a partir de critérios e número de vagas a serem estabelecidos pelo Poder Executivo.

Mas segundo documento da prefeitura do Rio de Janeiro (RIO DE JANEIRO, 2013), há os seguintes incrementos percentuais ao vencimento-base para o professor, considerando sua formação: ensino médio-licenciatura curta $12 \%$, licenciatura curta, licenciatura plena $12 \%$, licenciatura plena-especialização $3 \%$, licenciatura plena-mestrado $12 \%$, licenciatura plenadoutorado $15 \%$ e licenciatura plena-pós-doutorado 21\%. Ou seja, o PCCR de 1995 equiparava os percentuais no vencimento-base, embora fossem cumulativos, diferentemente do PCCR aprovado em 2013, em que há percentuais diferenciados na movimentação na carreira, que denotam maior valorização de títulos em nível de pós-graduação.

O Quadro 5 apresenta todas as titulações exigidas para o enquadramento nas classes dos planos de carreira do Rio de Janeiro:

7 De acordo com Dutra Junior et al. (2000, p. 215), vencimento “[...] é o valor mensal básico devido ao servidor público pelo exercício das funções inerentes ao cargo que ocupa. O valor correspondente ao cargo é indicado pelo respectivo padrão". 
Trabalho e Carreira Docente na Rede Municipal do Rio de Janeiro

Quadro 5 - Movimentação na carreira via titulação

\begin{tabular}{|c|c|c|c|}
\hline \multicolumn{2}{|c|}{ Lei municipal nº 2391/1995 } & \multicolumn{2}{|c|}{ Lei municipal $n^{\circ} 5623 / 2013$} \\
\hline Enquadramento & Titulação & Enquadramento & Titulação \\
\hline Classe A & $\begin{array}{l}\text { Nível médio - } \\
\text { modalidade normal }\end{array}$ & Classe A & $\begin{array}{l}\text { Nível Médio - } \\
\text { modalidade Normal }\end{array}$ \\
\hline Classe B & $\begin{array}{c}\text { Curso de Licenciatura } \\
\text { Curta ou estudos } \\
\text { adicionais }\end{array}$ & Classe B & $\begin{array}{c}\text { Licenciatura Curta ou } \\
\text { nível médio com } \\
\text { estudos adicionais }\end{array}$ \\
\hline Classe C & $\begin{array}{c}\text { Curso de Licenciatura } \\
\text { Plena }\end{array}$ & Classe C & $\begin{array}{c}\text { Curso de Licenciatura } \\
\text { Plena }\end{array}$ \\
\hline & & Classe D & $\begin{array}{l}\text { Pós-Graduação Stricto } \\
\text { Sensu: Mestrado com } \\
\text { dissertação defendida, } \\
\text { na área da Educação }\end{array}$ \\
\hline & & Classe A1 & $\begin{array}{l}\text { Pós-Graduação Lato } \\
\text { Sensu, de no mínimo } \\
360 \text { horas, na área da } \\
\text { Educação }\end{array}$ \\
\hline & & Classe A2 & $\begin{array}{c}\text { Pós-graduação: } \\
\text { Doutorado - com tese } \\
\text { defendida, na área da } \\
\text { Educação }\end{array}$ \\
\hline & & Classe A3 & $\begin{array}{l}\text { Pós- Doutorado com } \\
\text { tese defendida, na } \\
\text { área da Educação }\end{array}$ \\
\hline
\end{tabular}

Fonte: Rio de Janeiro (1995; 2013a).

A movimentação na carreira via tempo de serviço possui uma progressão vertical variável de interregnos, a partir do tempo de dedicação, seja na legislação anterior à greve de 2013, quanto na posterior à luta protagonizada pelos professores, variando a cada cinco anos para a mudança de enquadramento no vencimento-base, conforme pode se visualizar no quadro abaixo. Segundo esses dados, a amplitude da carreira dos trabalhadores da educação municipal do Rio de Janeiro possuía a duração de 30 anos, em ambos os planos de carreira, de 1995 e 2013. No intervalo dos PCCR analisados, houve uma alteração na nomenclatura do ponto em que o professor seria enquadrado: em 2008, segundo a Lei Municipal $n^{\circ}$ 4814/2008, que estabeleceu alterações para diversos cargos da Prefeitura do Rio de Janeiro, utilizava-se classe, a partir de 2013, nomeou-se nível (RIO DE JANEIRO, 2008). Em nenhuma das alterações legais foi estipulado um percentual de diferenciação salarial pelo enquadramento devido ao tempo de serviço. 
Trabalho e Carreira Docente na Rede Municipal do Rio de Janeiro

Quadro 6 - Movimentação na carreira via tempo de serviço

\begin{tabular}{|c|c|c|c|}
\hline \multicolumn{2}{|c|}{ Lei municipal $\mathbf{n}^{\mathbf{0}} \mathbf{4 8 1 4 / 2 0 0 8}$} & \multicolumn{2}{c|}{ Lei municipal $\mathbf{n}^{\mathbf{5 6 2 3 / 2 0 1 3}}$} \\
\hline Enquadramento & Tempo de serviço & Enquadramento & Tempo de serviço \\
\hline Classe A & 0 a 5 anos & Nível 1 & 0 a 5 anos \\
\hline Classe B & 5 a 8 anos & Nível 2 & 5 a 8 anos \\
\hline Classe C & 8 a 10 anos & Nível 3 & 8 a 10 anos \\
\hline Classe D & 10 a 15 anos & Nível 4 & 10 a 15 anos \\
\hline Classe E & 15 a 20 anos & Nível 5 & 15 a 20 anos \\
\hline Classe F & 20 a 25 anos & Nível 6 & 20 a 25 anos \\
\hline Classe G & mais de 25 anos & Nível 7 & mais de 25 anos \\
\hline
\end{tabular}

Fonte: Rio de Janeiro (2008; 2013a).

De acordo com as configurações estabelecidas na legislação anterior à greve de 2013, a tabela de vencimentos apresentava uma dispersão de vencimentos ${ }^{8}$ de $70 \%$, considerando o enquadramento no início da carreira (todos os cargos de 0 a 5 anos), na classe A-1 e final da carreira (todos os cargos de mais de 30 anos) A-7, assim como os cargos com os respectivos enquadramentos classe B-2 e C-3 (início) e classe B-7 e C-7 (final).

As tabelas a seguir representam a forma de movimentação na carreira docente do Rio de Janeiro, existente desde 2013, exibindo o plano para os cargos de Professor de Educação Infantil, Professor de Ensino Fundamental e Professor II, que também trabalha com educação infantil e ciclo I do ensino fundamental, em jornada de trabalho de 40 horas semanais, considerando-se a maior diversidade de enquadramento do vencimento-base, segundo a formação inicial.

No caso do Professor de Ensino Fundamental e Professor II, a primeira tabela de vencimento enquadra sua formação inicial em licenciatura plena, enquadrado na Classe C, podendo movimentar-se na carreira via titulação até o pós-doutorado, enquadrado na Classe A3, em jornada de 40 horas semanais. A dispersão do vencimento-base nessa carreira é de $22 \%$.

Tabela 1 - Tabela de vencimento Professor de Ensino Fundamental/Professor II em jornada de trabalho de 40 horas (Lei 5623/2013)

\begin{tabular}{|l|c|c|c|c|c|c|}
\hline Nível & Tempo de serviço & $\begin{array}{c}\text { Licenciatura } \\
\text { plena (Classe C) }\end{array}$ & $\begin{array}{c}\text { Lato sensu } \\
\text { (Classe A1) }\end{array}$ & $\begin{array}{c}\text { Mestrado } \\
\text { (Classe D) }\end{array}$ & $\begin{array}{c}\text { Doutorado } \\
\text { (Classe A2) }\end{array}$ & $\begin{array}{c}\text { Pós doutorado } \\
\text { (Classe A3) }\end{array}$ \\
\hline Nível 7 & Mais de 25 anos & $\mathrm{R} \$ 5.257,75$ & $\mathrm{R} \$ 5.405,18$ & $\mathrm{R} \$ 5.877,48$ & $\mathrm{R} \$ 6.034,91$ & $\mathrm{R} \$ 6.349,77$ \\
\hline Nível 6 & Mais de 20 até 25 anos & $\mathrm{R} \$ 5.405,91$ & $\mathrm{R} \$ 5.197,29$ & $\mathrm{R} \$ 5.651,42$ & $\mathrm{R} \$ 5.802,80$ & $\mathrm{R} \$ 6.105,55$ \\
\hline Nível 5 & Mais de 15 até 20 anos & $\mathrm{R} \$ 4.851,84$ & $\mathrm{R} \$ 4.997,39$ & $\mathrm{R} \$ 5.434,06$ & $\mathrm{R} \$ 5.579,61$ & $\mathrm{R} \$ 5.870,72$ \\
\hline Nível 4 & Mais de 10 até 15 anos & $\mathrm{R} \$ 4.665,23$ & $\mathrm{R} \$ 4.805,18$ & $\mathrm{R} \$ 5.225,05$ & $\mathrm{R} \$ 5.365,01$ & $\mathrm{R} \$ 5.644,92$ \\
\hline Nível 3 & Mais de 8 até 10 anos & $\mathrm{R} \$ 4.485,80$ & $\mathrm{R} \$ 4.620,37$ & $\mathrm{R} \$ 5.024,09$ & $\mathrm{R} \$ 5.158,66$ & $\mathrm{R} \$ 5.427,81$ \\
\hline Nível 2 & Mais de 5 até 8 anos & $\mathrm{R} \$ 4.313,26$ & $\mathrm{R} \$ 4.442,66$ & $\mathrm{R} \$ 4.830,86$ & $\mathrm{R} \$ 4.960,25$ & $\mathrm{R} \$ 5.219,05$ \\
\hline Nível 1 & De 0 a 5 anos & $\mathrm{R} \$ 4.147,37$ & $\mathrm{R} \$ 4.271,79$ & $\mathrm{R} \$ 4.645,05$ & $\mathrm{R} \$ 4.769,48$ & $\mathrm{R} \$ 5.018,32$ \\
\hline
\end{tabular}

Fonte: Rio de Janeiro (2013a).

A segunda tabela de vencimento apresenta o enquadramento do vencimento-base dos cargos de Professor II, Professor de Ensino Especializado (que atua em educação especial)

8 Dispersão pode ser definida como "[...] a distância entre a menor e a maior remuneração que correspondem, respectivamente, ao início e ao fim da carreira de uma determinada categoria profissional" (DUTRA JÚNIOR et al., 2000, p. 131). 
e Professor de Educação Infantil, em jornada de trabalho de 22,5 horas, tendo sua formação inicial em nível médio, enquadrado na Classe A, podendo movimentar-se na carreira até atingir o título de mestre, Classe D. Nessa carreira, a dispersão do vencimento-base é de $10 \%$.

\section{Tabela 2 - Tabela de vencimento Professor II/Professor de Ensino Especializado/Professor de Educação Infantil em jornada de trabalho de 22,5 horas (Lei 5623/2013)}

\begin{tabular}{|l|c|c|c|c|c|}
\hline Nível & Tempo de serviço & $\begin{array}{c}\text { Ensino médio } \\
\text { (Classe A) }\end{array}$ & $\begin{array}{c}\text { Licenciatura curta } \\
\text { (Classe } B \text { ) }\end{array}$ & $\begin{array}{c}\text { Licenciatura plena } \\
\text { (Classe C) }\end{array}$ & $\begin{array}{c}\text { Mestrado } \\
\text { (Classe D) }\end{array}$ \\
\hline Nível 7 & Mais de 25 anos & $\mathrm{R} \$ 1.673,39$ & $\mathrm{R} \$ 1.874,20$ & $\mathrm{R} \$ 2.099,10$ & $\mathrm{R} \$ 2.350,99$ \\
\hline Nível 6 & Mais de 20 até 25 anos & $\mathrm{R} \$ 1.609,03$ & $\mathrm{R} \$ 1.802,11$ & $\mathrm{R} \$ 2.018,37$ & $\mathrm{R} \$ 2.260,57$ \\
\hline Nível 5 & Mais de 15 até 20 anos & $\mathrm{R} \$ 1.547,14$ & $\mathrm{R} \$ 1.732,80$ & $\mathrm{R} \$ 1.940,74$ & $\mathrm{R} \$ 2.173,63$ \\
\hline Nível 4 & Mais de 10 até 15 anos & $\mathrm{R} \$ 1.487,64$ & $\mathrm{R} \$ 1.666,15$ & $\mathrm{R} \$ 1.866,09$ & $\mathrm{R} \$ 2.090,02$ \\
\hline Nível 3 & Mais de 8 até 10 anos & $\mathrm{R} \$ 1.430,42$ & $\mathrm{R} \$ 1.602,07$ & $\mathrm{R} \$ 1.794,32$ & $\mathrm{R} \$ 2.009,64$ \\
\hline Nível 2 & Mais de 5 até 8 anos & $\mathrm{R} \$ 1.375,40$ & $\mathrm{R} \$ 1.540,45$ & $\mathrm{R} \$ 1.725,31$ & $\mathrm{R} \$ 1.932,34$ \\
\hline Nível 1 & De 0 a 5 anos & $\mathrm{R} \$ 1.322,50$ & $\mathrm{R} \$ 1.481,21$ & $\mathrm{R} \$ 1.658,95$ & $\mathrm{R} \$ 1.858,02$ \\
\hline
\end{tabular}

Fonte: Rio de Janeiro (2013a).

A terceira tabela apresenta as possibilidades de movimentação na carreira do Professor de Educação Infantil, em jornada de trabalho de 40 horas, com ingresso na carreira possuindo formação em nível médio, enquadrado na Classe $A$, podendo atingir a Classe $A 3$, com titulação de pós-doutorado, com dispersão de $30 \%$ no vencimento-base.

Tabela 3 - Tabela de vencimento Professor de Educação Infantil em jornada de trabalho de 40 horas (Lei 5623/2013)

\begin{tabular}{|c|c|c|c|c|c|c|c|c|}
\hline Nível & Tempo de serviço & $\begin{array}{l}\text { Ensino } \\
\text { médio } \\
\text { (Classe A) }\end{array}$ & $\begin{array}{l}\text { Licenciatura } \\
\text { curta (Classe } \\
\text { B) }\end{array}$ & $\begin{array}{c}\text { Licenciatura } \\
\text { plena (Classe } \\
\text { C) }\end{array}$ & $\begin{array}{c}\text { Especialiação } \\
\text { (Classe A1) }\end{array}$ & $\begin{array}{l}\text { Mestrado } \\
\text { (Classe D) }\end{array}$ & $\begin{array}{l}\text { Doutorado } \\
\text { (Classe A2) }\end{array}$ & $\begin{array}{c}\text { Pós } \\
\text { doutorado } \\
\text { (Classe A3) }\end{array}$ \\
\hline Nível 7 & Mais de 25 anos & $\$ 4.183,47$ & $\$ 4.685,49$ & $\mathrm{R} \$ 5.247,75$ & $\mathrm{R} \$ 5.405,18$ & $2 \$ 5.877,48$ & $\mathrm{R} \$ 6.034,91$ & $\mathrm{R} \$ 6.349,78$ \\
\hline Nível 6 & Mais de 20 até 25 anos & $\mathrm{R} \$ 4.022,57$ & $\mathrm{R} \$ 4.505,28$ & $R \$ 5.045,91$ & $R \$ 5.197,29$ & $\mathrm{R} \$ 5.651,42$ & $\mathrm{R} \$ 5.802,80$ & $\mathrm{R} \$ 6.105,55$ \\
\hline Nível 5 & Mais de 15 até 20 anos & $\mathrm{R} \$ 3.867,86$ & $\mathrm{R} \$ 4.332,00$ & $\mathrm{R} \$ 4.851,84$ & $\mathrm{R} \$ 4.997,39$ & $\mathrm{R} \$ 5.434,06$ & $R \$ 5.579,62$ & $\mathrm{R} \$ 5.870,73$ \\
\hline Nível 4 & Mais de 10 até 15 anos & $\mathrm{R} \$ 3.719,09$ & $\mathrm{R} \$ 4.165,38$ & $\mathrm{R} \$ 4.665,23$ & $\mathrm{R} \$ 4.805,19$ & $\mathrm{R} \$ 5.225,06$ & $\mathrm{R} \$ 5.385,01$ & $\mathrm{R} \$ 5.644,93$ \\
\hline Nível 3 & Mais de 8 até 10 anos & $\mathrm{R} \$ 3.576,05$ & $\mathrm{R} \$ 4.005,18$ & $\mathrm{R} \$ 4.485,80$ & $\mathrm{R} \$ 4.620,37$ & $\mathrm{R} \$ 5.024,09$ & $\mathrm{R} \$ 5.158,67$ & $\mathrm{R} \$ 5.427,82$ \\
\hline Nível 2 & Mais de 5 até 8 anos & $\mathrm{R} \$ 3.438,51$ & $R \$ 3.851,13$ & $R \$ 4.313,27$ & $\mathrm{R} \$ 4.442,67$ & $\mathrm{R} \$ 4.830,86$ & $\mathrm{R} \$ 4.960,26$ & $R \$ 5.219,05$ \\
\hline Nível 1 & De 0 a 5 anos & $\mathrm{R} \$ 3.306,26$ & $\mathrm{R} \$ 3.703,01$ & $\mathrm{R} \$ 4.147,37$ & $\mathrm{R} \$ 4.271,79$ & $\mathrm{R} \$ 4.645,06$ & $\mathrm{R} \$ 4.769,48$ & $\mathrm{R} \$ 5.018,32$ \\
\hline
\end{tabular}

Fonte: Rio de Janeiro (2013a).

A quarta tabela de vencimento apresenta a possibilidade de movimentação na carreira do Professor II, com jornada de trabalho de 40 horas, ingressante na carreira com formação em nível médio, enquadrado na Classe $A$, atingindo a Classe $D$ com título de mestre, apresentando uma dispersão de $26 \%$ no vencimento-base.

Tabela 4 - Tabela de vencimento Professor II com jornada de trabalho de 40 horas (Lei 5623/2013)

\begin{tabular}{|c|c|c|c|c|c|}
\hline Nível & Tempo de serviço & $\begin{array}{c}\text { Ensino médio } \\
\text { (Classe A) }\end{array}$ & $\begin{array}{c}\text { Licenciatura curta } \\
\text { (Classe B) }\end{array}$ & $\begin{array}{c}\text { Licenciatura plena } \\
\text { (Classe C) }\end{array}$ & $\begin{array}{c}\text { Mestrado } \\
\text { (Classe D) }\end{array}$ \\
\hline Nível 7 & Mais de 25 anos & $\mathrm{R} \$ 4.183,47$ & $\mathrm{R} \$ 4.685,49$ & $\mathrm{R} \$ 5.247,75$ \\
\hline Nível 6 & Mais de 20 até 25 anos & $\mathrm{R} \$ 4.022,57$ & $\mathrm{R} \$ 4.505,28$ & $\mathrm{R} \$ 5.045,21$ & $\mathrm{R} \$ 5.651,42$ \\
\hline Nível 5 & Mais de 15 até 20 anos & $\mathrm{R} \$ 3.867,85$ & $\mathrm{R} \$ 4.332,00$ & $\mathrm{R} \$ 4.851,84$ & $\mathrm{R} \$ 5.434,06$ \\
\hline Nível 4 & Mais de 10 até 15 anos & $\mathrm{R} \$ 3.719,09$ & $\mathrm{R} \$ 4.165,38$ & $\mathrm{R} \$ 4.665,23$ & $\mathrm{R} \$ 5.225,05$ \\
\hline Nível 3 & Mais de 8 até 10 anos & $\mathrm{R} \$ 3.576,05$ & $\mathrm{R} \$ 4.005,17$ & $\mathrm{R} \$ 4.485,80$ \\
\hline Nível 2 & Mais de 5 até 8 anos & $\mathrm{R} \$ 3.438,51$ & $\mathrm{R} \$ 3.851,13$ & $\mathrm{R} \$ 4.313,26$ \\
\hline Nível 1 & De 0 a 5 anos & $\mathrm{R} \$ 3.306,26$ & $\mathrm{R} \$ 3.703,01$ & $\mathrm{R} \$ 4.147,37$ & $\mathrm{R} \$ 4.83,09$ \\
\hline
\end{tabular}

Fonte: Rio de Janeiro (2013a). 
Trabalho e Carreira Docente na Rede Municipal do Rio de Janeiro

A partir das alterações previstas na Lei $n^{\circ} 5623 / 2013$, a dispersão do vencimento-base é variável segundo o cargo ocupado pelo professor. Dentre as tabelas de vencimento apresentadas, o ingresso na carreira de Professor II/Professor de Ensino Especializado/Professor de Educação Infantil jornada de 22,5 horas possui a dispersão mais baixa e pode indicar pouca atratividade em relação a essa carreira, além disso, o vencimentobase oferecido estava abaixo do piso salarial no ano de 2013 , cujo valor era de $\mathrm{R} \$ 1.567,00$.

No caso das carreiras com jornada de 40 horas semanais: Professor de Ensino Fundamental/Professor II, Professor de Educação Infantil e Professor II, seus vencimentosbase são competitivos acima do piso salarial, contudo, suas baixas dispersões salariais e acréscimo de $3 \%$ entre as titulações tornam a movimentação na carreira via titulação pouco estimulante à formação acadêmica.

No que se refere à tendência de equiparação salarial entre professores da educação infantil e do ensino fundamental, há alguns avanços e recuos. Há equiparação no valor do vencimento para docentes que trabalham em diferentes modalidades, resguardando, entre si, diferenças nos vencimentos pelo critério da titulação e da jornada de trabalho, sobretudo os trabalhadores ingressantes na jornada de 40 horas semanais.

Como se observou nos quadros de vencimento exibidos, no caso dos cargos de PEI e PEF, com a referida jornada e formação em nível superior, seus vencimentos-base iniciais possuíam valor de $\mathrm{R} \$ 4.147,37$. Mas, no caso de ocupantes do cargo de Professor II, Professor de Ensino Especializado e Professor de Educação Infantil, com títulos de mestre, em jornada de 22 horas e 30 minutos semanais, seu vencimento-base, no final da carreira, pode atingir o valor de $\mathrm{R} \$ 1.858,02$, menor que o dobro desses cargos mencionados que possuem jornada de 40 horas semanais. O que denota não haver isonomia na estrutura da carreira entre professores com a mesma formação inicial.

O PCCR, aprovado em 2013, diferentemente do anterior, contempla a progressão na carreira via titulação até doutorado, no entanto, apenas para os cargos de Professor de Ensino Fundamental e Professor II (ambos os cargos trabalham com ciclo 1 do ensino fundamental) que ingressam com ensino superior, na jornada de 40 horas semanais, e para Professor de Educação Infantil com a mesma jornada. As demais categorias, todavia, continuam com, praticamente, a mesma configuração, sendo possível obter progressões no vencimento até o mestrado. Além disso, embora seja estabelecido no PCCR essa valorização da formação acadêmica em pós-graduação, a movimentação obtida por essa via não é uma garantia como direito, pois, como foi apontado, está restrita a critérios de vagas não explicitados no PCCR e à disponibilidade orçamentária.

Tal realidade abre diversos precedentes para que o professor que possua titulações não necessariamente altere seu enquadramento na carreira, podendo permanecer numa mesma classe de vencimento, restando-lhe "aguardar" a progressão via tempo de serviço.

\section{Componentes da remuneração}

O quadro abaixo apresenta, em síntese, a remuneração docente da rede municipal do Rio de Janeiro, considerando os componentes presentes na legislação anterior à greve de 2013 e aqueles que se mantiveram, ou possuem outras configurações a partir do PCCR de 2013. 
Trabalho e Carreira Docente na Rede Municipal do Rio de Janeiro

Quadro 7 - Composição da remuneração docente na rede municipal do Rio de Janeiro

\begin{tabular}{|c|c|c|}
\hline $\begin{array}{l}\text { Componentes da } \\
\text { remuneração }\end{array}$ & Anterior a 2013 & 2013 \\
\hline Vencimento & $\begin{array}{c}\text { Diferenciação por titulação e por tempo de } \\
\text { serviço }\end{array}$ & $\begin{array}{c}\text { Diferenciação por titulação e por tempo de } \\
\text { serviço }\end{array}$ \\
\hline Gratificações & Gratificação de difícil acesso & $\begin{array}{c}\text { Gratificação de difícil acesso } \\
\text { Gratificação por serviço noturno } \\
\text { Gratificação pelo exercício de direção }\end{array}$ \\
\hline Adicionais & $\begin{array}{c}\text { Triênio } \\
\text { Adicional de qualificação para o exercício do } \\
\text { cargo }\end{array}$ & $\begin{array}{l}\text { Triênio } \\
\text { Sexta parte }\end{array}$ \\
\hline Auxílios & $\begin{array}{l}\text { Auxílio transporte } \\
\text { Benefício-alimentação } \\
\text { Auxílio educação }\end{array}$ & $\begin{array}{l}\text { Auxílio transporte } \\
\text { Benefício-alimentação } \\
\text { Auxílio educação } \\
\text { Auxílio doença }\end{array}$ \\
\hline
\end{tabular}

Fonte: Elaborado pelo autor.

O primeiro elemento componente da remuneração docente é o vencimento-base. $\mathrm{Na}$ seção anterior, foi realizada uma análise desse elemento, considerando que pode diferenciarse no PCCR, anterior ou posterior a 2013, a partir de critérios que se valem do tempo de serviço e da titulação obtida pelos professores ocupantes de diferentes cargos.

Um segundo elemento de composição da remuneração docente em ambos os planos de carreira é o adicional por tempo de serviço, triênios. Segundo o Estatuto dos funcionários públicos do município do Rio de Janeiro (RIO DE JANEIRO, 1979), ao completar 3 anos de serviço, ou seja, após a passagem do período probatório, o servidor tem a incorporação de $10 \%$ adicionais ao vencimento-base, e nos demais períodos o aumento, a cada 3 anos, é de $5 \%$, até atingir o limite de $65 \%$.

Um terceiro elemento, que não esteve presente na Lei $n^{\circ} 2391 / 1995$, é a previsão de sexta parte. No PCCR aprovado em 2013 é contemplada essa dimensão de valorização do tempo de trabalho, a sexta parte, que, na Lei Orgânica do município do Rio de Janeiro (RIO DE JANEIRO, 2010) é obtida ao atingir-se 20 anos de trabalho e se incorpora ao vencimento.

O quarto elemento que compõe a remuneração, em ambos os planos analisados, é a gratificação de difícil acesso, para os professores que realizarem seu trabalho em unidades escolares localizadas em morros ou ladeiras íngremes, que devam ser vencidos em condições difíceis, situadas em locais servidos de, no máximo, duas linhas regulares de transportes coletivos, localizadas a um quilômetro ou mais do ponto de transporte coletivo, exigindo do professor a realização de longo percurso a pé (RIO DE JANEIRO, 2003). Essa gratificação incide sobre o vencimento-base com percentuais diferenciados, a depender do cargo ocupado pelo professor: $15 \%$ para Professor II e 10\% para Professor I, segundo Lei municipal $n^{\circ}$ 1881/1992 (RIO DE JANEIRO, 1992); 15\% para Professor I, com jornada de trabalho de 30 e 40 horas semanais, Professor II, PEI e PEF e 10\% para Professor I, com jornada de trabalho de 16 horas semanais, segundo a Lei $n^{\circ}$ 5623/2013.

O quinto componente de remuneração é a gratificação pelo exercício de direção, direção adjunta ou coordenação pedagógica de unidades escolares, presente somente no PCCR aprovado em 2013 e sem um estabelecimento de percentuais de diferenciação salarial ${ }^{9}$.

9 O Projeto de Lei que regulamentaria essa gratificação teve sua tramitação suspensa em 30/11/2016. Disponível em: <mail.camara.rj.gov.br/APL/Legislativos/scpro1316.nsf/249cb321f17965260325775900523a42/157c3ac7023078ea83 25805300660ed4?OpenDocument>. Acesso em: 16 dez. 2016. 
Trabalho e Carreira Docente na Rede Municipal do Rio de Janeiro

Um sexto elemento da remuneração é o adicional de qualificação para o exercício do cargo, que estava presente somente na legislação anterior à greve de 2013 , na Lei $n^{\circ}$ 2391/1995. Esse adicional é obtido por meio da contabilização da soma de cargas horárias de cursos dos quais o professor tenha participado, relacionados à função exercida e ministrados por órgãos legalmente reconhecidos pelo Ministério da Educação (MEC), pela Secretaria de Estado de Educação do Rio de Janeiro ou pela Secretaria Municipal de Educação do Rio de Janeiro. Pode-se fazer jus ao adicional de qualificação nos períodos de afastamento considerados como de efetivo exercício pela legislação em vigor e nas licenças para tratamento de saúde.

\section{Quadro 8 - Cargas horárias para obtenção do adicional de qualificação}

\begin{tabular}{|c|c|}
\hline Somatório das cargas horárias & $\begin{array}{c}\text { Percentual de gratificação sobre o } \\
\text { vencimento (em \%) }\end{array}$ \\
\hline 150 horas & 2,5 \\
\hline 300 horas & 5,0 \\
\hline 450 horas & 7,5 \\
\hline 600 horas & 10,0 \\
\hline 750 horas & 12,5 \\
\hline 900 horas & 15,0 \\
\hline 1.050 horas & 17,5 \\
\hline 1.200 horas & 20,0 \\
\hline & Fonte: Rio de Janeiro (1995). \\
\hline
\end{tabular}

No que tange aos auxílios, tratam-se de políticas que parecem ter uma tendência de continuidade nas condições de trabalho vigentes durante e após a greve de 2013, visto que estão presentes em legislação complementar ou em decretos e destinam-se ao conjunto do funcionalismo público municipal.

O sétimo elemento da composição da remuneração refere-se ao auxílio educação. Implementado pelo Decreto $n^{\circ} 30.543 / 2009$ (RIO DE JANEIRO, 2009), esse auxílio constituise de um conjunto de medidas assistenciais do Instituto de Previdência e Assistência do Rio de Janeiro (Prev-Rio) que cobre funcionários públicos de diferentes faixas salariais. No que se refere aos trabalhadores da educação, consta no auxílio educação o Previ-MaterialEscolar, destinado, exclusivamente, a filhos de funcionários ativos e inativos, e tem por finalidade subsidiar, no valor de $\mathrm{R} \$ 50,00$, a quem tenha apenas um filho, ampliando-se para $\mathrm{R} \$ 100,00$ ao funcionário que tiver mais de um filho, para a aquisição de material didático necessário ao desenvolvimento e educação de filhos que contarem com menos de 18 anos, na data de 31 de dezembro do ano anterior ao período de inscrição. Para a concessão do auxílio educação em suas modalidades, os filhos de funcionários devem estar cadastrados nos programas assistenciais do município.

Um oitavo elemento que pode compor a remuneração é o auxílio transporte. Segundo o Decreto 17.110/1998 (RIO DE JANEIRO, 1998), esse tipo de benefício é suspenso durante o período de férias, licença ou afastamento, a qualquer título, ou falta, ainda que justificada, salvo ocorrência de trabalho externo.

O nono componente da remuneração refere-se ao auxílio alimentação, denominado na legislação municipal de benefício-alimentação (RIO DE JANEIRO, 2001). Fornecido em ticket 
Trabalho e Carreira Docente na Rede Municipal do Rio de Janeiro

ou arrendamento aos servidores municipais que recebam até 07 salários mínimos de remuneração. $O$ universo de destinatários do benefício-alimentação é refixado mensalmente, em decorrência das alterações, com inclusões e exclusões, inclusive férias, dos servidores beneficiados. O benefício-alimentação não é convertido em pecúnia e nem incorporado ao vencimento e vantagens do servidor.

O décimo elemento que pode compor a remuneração é o auxílio doença, que estava presente somente no PCCR de 2013. Com esse auxílio, o funcionário recebe o correspondente a um mês de vencimento, após cada período de 12 meses consecutivos de licença para tratamento de saúde.

\section{Considerações finais}

Uma avaliação geral dos dois Planos de Carreira, aqui descritos e analisados, permite algumas conclusões preliminares. É importante que o ingresso na carreira docente tenha se mantido por meio de concurso público de provas e títulos, pois, além de combater práticas clientelistas e de indicação, é assegurado no concurso público um processo de seleção de profissionais melhor preparados, diante dos requisitos que os concursos conseguem aferir (ARELARO et al., 2012).

Em relação à jornada de trabalho, embora esteja expressa na legislação a diversificação de atividades que compõem as horas de trabalho, e que a profissionalização docente seja discurso recorrente nas agendas de governos, é preciso que os planos de carreira valorizem a importância dos trabalhadores da educação na sociedade contemporânea, de modo que atraia professores com boa formação e permita uma jornada de trabalho compatível com a especificidade do trabalho docente (JACOMINI; PENNA, 2016).

Contudo, a partir da análise do PCCR, o que se verifica é o contrário da reivindicação de carreira unificada entre os trabalhadores da educação, pois o PCCR aprovado parece ser uma junção de diferentes planos, ou seja, impõe diferentes formas de movimentação na carreira para cada cargo, também gera falsa expectativa no regime de 40 horas e não oferece a migração de professores para essa jornada, que, como exposto no Gráfico 2, já compõe um universo restrito de apenas $6 \%$ de professores da rede.

A restrição orçamentária apresentou-se como mais um limite na conquista de direitos quando se analisa a jornada de trabalho de 40 horas semanais do magistério. Por um lado, tal carga horária se revela como uma conquista, ou adequação, às normativas nacionais para criação de carreiras, que estabelecem a jornada de 40 horas com dedicação exclusiva a uma escola, podendo o professor desenvolver com melhores condições projetos pedagógicos, desde que lhe sejam assegurados na jornada horários específicos para planejamento coletivo e formação continuada. No entanto, por outro lado, a implementação dessa política de carreira do Rio de Janeiro ocorre mediante a disponibilidade orçamentária do município, o que possivelmente deve impor empecilhos ao docente que queira exercer a jornada integral como um direito.

No PCCR aprovado em 2013, em caráter emergencial e num cenário de repressão contra os professores cariocas, a dimensão de movimentação na carreira apresenta percentuais menores do que aquele proposto pelos professores em greve, no que tange à progressão obtida pela titulação (licenciatura $12 \%$, especialização $3 \%$, mestrado $12 \%$, 
Trabalho e Carreira Docente na Rede Municipal do Rio de Janeiro

doutorado $15 \%$ e pós-doutorado $21 \%$ ) e pelo tempo de serviço ( $4 \%$ a cada 5 anos de trabalho).

Além disso, o PCCR aprovado apresenta muitas limitações quando se analisam aspectos da movimentação na carreira. A valorização da formação em pós-graduação, mestrado, doutorado, pós-doutorado toma um contorno de estratificação entre o magistério pelo fato de constituir-se em carreiras praticamente diferentes para professores com graduação e professores com pós-graduação. Essa valorização no atual PCCR corre o sério risco de converter-se em fragmentação de pequenas camadas de professores doutores na rede municipal, ou mesmo nem existir, pelo fato de a prefeitura do Rio de Janeiro restringir, sob limites orçamentários, os trabalhadores da educação que atingirão essa posição no plano de carreira. A movimentação via titulação, nesse PCCR, não é garantida como um direito, o que pode gerar frustrações, fazendo o docente permanecer numa mesma classe na tabela de vencimentos, restando-lhe "aguardar" a movimentação por tempo de serviço ou ser retido por outra rede de ensino que valorize sua formação, como no ensino superior público ou privado.

Considerando esses elementos, é passível de interpretação que o investimento na formação continuada se torna, em geral, uma prerrogativa para incrementar o vencimento no plano de carreira, e não uma ferramenta de melhoria da qualidade do ensino e do aperfeiçoamento docente. Fazendo, desse modo, com que o plano de carreira se torne uma legislação que faz sentido, principalmente, pelas condições de trabalho e de remuneração que oferece, e não como mais uma ferramenta que se refere à valorização do trabalho na escola, sem, de fato, garanti-la.

Para o trabalho do professor, a atividade que desenvolve não tem por motivo apenas o salário. Nesse sentido, para o êxito positivo do trabalho pedagógico, o salário não pode ser apenas uma compensação pelo exercício laboral, como ocorre no setor privado. Em oposição a isso, a remuneração justa do professor, associada a um maior financiamento da educação pública, são alguns dos requisitos necessários para que haja condições objetivas adequadas à realização da atividade que esse profissional tem por incumbência desenvolver: a formação do educando (PARO, 2011).

As políticas de carreira docente devem incentivar contribuir para a ampliação de sua formação, valorizando-a, respaldada por uma concepção sobre a natureza do trabalho pedagógico e que tenha por objetivo a melhoria da qualidade do ensino e, assim, da formação dos estudantes.

\section{Referências}

ALENCAR, Felipe Willian Ferreira de. Das Jornadas de Junho ao "Fora Cabral, vá com Paes!": um estudo sobre a greve de professores da Rede Municipal do Rio de Janeiro (2013). In: SEMANA DE PÓS-GRADUAÇÃO EM CIÊNCIAS SOCIAIS, 1, 2018, Guarulhos. Anais... Guarulhos, 2018. v. 1. p. 399-408. Disponível em <possecs1.files.wordpress.com/2018/08/ anais-i-semana-de-pc3b3s-graduac3a7c3a3o-cic3aancias-sociaisunifesp_completo_vs2.pdf>. Acesso em: 24 mar. 2019.

ARELARO, Lisete Regina Gomes. Fundef: uma avaliação preliminar dos dez anos de sua implantação. In: REUNIÃO ANUAL DA ANPED, 33, 2007, Caxambu. Anais... Caxambu: Anped, 2007. 
Trabalho e Carreira Docente na Rede Municipal do Rio de Janeiro

ARELARO, Lisete Regina Gomes et al. Trabalho docente e valorização do magistério na Rede Municipal de Ensino de São Paulo. Educação em foco, Belo Horizonte, ano 15, n. 19, p. 129162, jun. 2012.

ARELARO, Lisete Regina Gomes et al. Condições do trabalho docente: uma análise da carreira na rede municipal de ensino de São Paulo. Revista Brasileira de Estudos Pedagógicos, Brasília, v. 95, n. 239, p. 197-217, jan./abr. 2014.

BRASIL. Lei $n^{\circ}$ 9.394, de 20 de dezembro de 1996. Estabelece as Diretrizes e Bases da Educação Nacional. Diário Oficial da União, Brasília, 1996a.

BRASIL. Lei no 9.424 de 24 de dezembro de 1996. Dispõe sobre o Fundo de Manutenção e Desenvolvimento do Ensino Fundamental e Valorização do Magistério. Diário Oficial da União, Brasília, 1996b.

BRASIL. Lei $n^{\circ} 11.494$, de 20 de junho de 2007. Regulamenta o Fundo de Manutenção e Desenvolvimento da Educação Básica e de Valorização dos Profissionais da Educação FUNDEB. Diário Oficial da União, Brasília, 2007.

BRASIL. Lei n 11.738, de 16 de julho de 2008. Regulamenta a alínea "e" do inciso III do caput do art. 60 do Ato das Disposições Constitucionais Transitórias, para instituir o piso salarial profissional nacional para os profissionais do magistério público da educação básica. Diário Oficial da União, Brasília, 2008.

BRASIL. Conselho Nacional de Educação. Câmara de Educação Básica. Resolução $n^{\circ} 2$, de 28 de maio de 2009. Fixa as Diretrizes Nacionais para os Planos de Carreira e Remuneração dos Profissionais do Magistério da Educação Básica Pública. Diário Oficial da União, Brasília, 29 maio 2009.

BRASIL. Conselho Nacional de Educação. Câmara de Educação Básica. Parecer $\mathbf{n}^{\circ}$ 12, de 2 de outubro de 2012. Reexame do Parecer CNE/CEB n 9/2012, que trata da implantação da Lei $n^{\circ} 11.738 / 2008$, que institui o piso salarial profissional nacional para os profissionais do magistério público da Educação Básica. Brasília, 2012.

CAMARGO, Rubens Barbosa et al. Financiamento da educação e remuneração docente: começo de conversa em tempos de piso salarial. Revista Brasileira de Política e Administração da Educação, Porto Alegre, v. 25, n. 2, p. 341-363, maio/ago. 2009.

CAMARGO, Rubens Barbosa; JACOMINI, Márcia Aparecida. Carreira e salário do pessoal docente da Educação Básica: algumas demarcações legais. Educação em Foco, Belo Horizonte, n. 17, p. 129-167, jul. 2011.

DAVIES, Nicholas. FUNDEB: a redenção da educação básica? Campinas: Autores Associados, 2008.

DUTRA JÚNIOR, Adhemar Ferreira et al. Plano de carreira e remuneração do magistério público: LDB, Fundef, Diretrizes nacionais e nova concepção de carreira. Brasília: Fundescola/MEC, 2000.

GATTI, Bernardete Angelina; BARRETO, Elba Siqueira de Sá; ANDRÉ, Marli Eliza Dalmazo Afonso. Políticas docentes no Brasil: um estado da arte. Brasília: UNESCO, 2011. 
Trabalho e Carreira Docente na Rede Municipal do Rio de Janeiro

GOUVEIA, Andréa Barbosa et al. Condições de trabalho docente, ensino de qualidade, e custo-aluno-ano. Revista Brasileira de Política e Administração da Educação, São Paulo, v. 22, n. 2, p. 253-276, jul./dez. 2006.

JACOMINI, Márcia Aparecida; PENNA, Marieta Gouvêia de Oliveira. Carreira docente e valorização do magistério: condições de trabalho e desenvolvimento profissional. Proposições, Campinas, v. 27, n. 2, p. 177-202, maio/ago. 2016.

MINHOTO, Maria Angélica Pedra; GIGLIO, Célia Maria Benedicto. Plano de cargos, carreira e remuneração do magistério público municipal de Boa Vista $(R R)$ : uma análise da valorização e do estímulo ao trabalho docente. Jornal de Políticas Educacionais, Curitiba, v. 5, n. 10, p. 36-45, ago./dez. 2012.

MONLEVADE, João Antônio Cabral de. Valorização salarial dos professores: o papel do Piso Salarial Profissional Nacional como instrumento de valorização dos professores da educação básica pública. 2000. Tese (Doutorado em Educação) - Faculdade de Educação, Universidade Estadual de Campinas, Campinas, 2000.

OLIVEIRA, Dalila Andrade. Os trabalhadores da educação e a construção política da profissão docente no Brasil. Educar em Revista, Curitiba, n. especial, p. 17-35, 2010.

PARO, Vitor Henrique. Crítica da estrutura da escola. São Paulo: Cortez, 2011.

RIO DE JANEIRO. Lei municipal n 94, de 14 de março de 1979. Dispõe sobre o Estatuto dos Funcionários Públicos do Poder Executivo do Município do Rio de Janeiro e dá outras providências. Diário Oficial do Município do Rio de Janeiro, Rio de Janeiro, 1979.

RIO DE JANEIRO. Lei Municipal $n^{\circ} 1881$, de 23 de julho de 1992. Dispõe sobre o plano de cargos, carreiras e remuneração dos servidores da Secretaria Municipal de Educação. Diário Oficial do Município do Rio de Janeiro, Rio de Janeiro, 1992.

RIO DE JANEIRO. Lei $\mathrm{n}^{\circ}$ 2.391, de 8 de dezembro de 1995. Institui o Plano de Cargos, Carreiras e Remuneração dos Profissionais do Magistério Público e de Apoio à Educação. Diário Oficial do Município do Rio de Janeiro, Rio de Janeiro, 1995.

RIO DE JANEIRO. Decreto $n^{\circ} 17042$ de 30 de setembro de 1998. Dispõe sobre a concessão de gratificação de encargos especiais aos integrantes do quadro de pessoal de apoio à educação. Diário Oficial do Município do Rio de Janeiro, Rio de Janeiro, 1998.

RIO DE JANEIRO. Decreto $n^{\circ} 19617$ de 6 de março de 2001. Dispõe sobre a concessão do benefício-alimentação aos servidores municipais da Administração Direta, Indireta e Fundacional e demais procedimentos a serem adotados. Diário Oficial do Município do Rio de Janeiro, Rio de Janeiro, 2001.

RIO DE JANEIRO. Decreto $n^{\circ} 23020$ de 17 de junho de 2003. Dispõe sobre a gratificação pelo exercício de atividades em unidades escolares situadas em local de difícil acesso. Diário Oficial do Município do Rio de Janeiro, Rio de Janeiro, 2003.

RIO DE JANEIRO. Lei municipal $n^{\circ} 4.814$ de 18 de abril de 2008. Dispõe sobre as categorias funcionais que menciona. Diário Oficial do Município do Rio de Janeiro, Rio de Janeiro, 2008. 
Trabalho e Carreira Docente na Rede Municipal do Rio de Janeiro

RIO DE JANEIRO. Decreto $n^{\circ} 30.543$ de 18 de março de 2009. Regulamenta as atividades assistenciais do Instituto de Previdência e Assistência do Município do Rio de Janeiro. Diário Oficial do Município do Rio de Janeiro, Rio de Janeiro, 2009.

RIO DE JANEIRO. Lei Orgânica do Município. Rio de Janeiro: Centro de Estudos da Procuradoria-Geral do Município, 2010.

RIO DE JANEIRO. Lei Municipal $n^{\circ} 5623$, de 1 de outubro de 2013. Dispõe sobre o Plano de Cargos, Carreiras e Remuneração dos funcionários da Secretaria Municipal de Educação. Diário Oficial do Município do Rio de Janeiro, Rio de Janeiro, 2013a.

RIO DE JANEIRO. Plano de cargos, carreira e remuneração da Educação. Prefeitura municipal do Rio de Janeiro, 2013b.

ROLNIK, Raquel. Apresentação - As vozes das ruas: as revoltas de junho e suas interpretações. In: MARICATO, Ermínia et al. Cidades rebeldes: Passe Livre e as manifestações que tomaram as ruas do Brasil. São Paulo: Boitempo, 2013. p. 7-12.

SECCO, Lincoln. Jornadas de Junho. In: MARICATO, Ermínia et al. Cidades rebeldes: Passe Livre e as manifestações que tomaram as ruas do Brasil. São Paulo: Boitempo, 2013. p. 7178.

SEPE. Sindicato Estadual dos Profissionais da Educação do Rio de Janeiro. Boletim do Sepe, Rio de Janeiro, 2013a.

SEPE. Sindicato Estadual dos Profissionais da Educação do Rio de Janeiro. Rede Municipal mantém greve e faz passeata com 20 mil. Boletim do Sepe, Rio de Janeiro, 2013b.

SEPE. Sindicato Estadual dos Profissionais da Educação do Rio de Janeiro. Mais de 50 mil nas ruas em defesa da educação e contra a violência do Estado. Boletim do Sepe, Rio de Janeiro, 2013c.

SOUZA, Ângelo Ricardo de et al. Planos de Carreiras da Rede Estadual de Ensino do Paraná e Rede Municipal de Ensino de Curitiba: um exercício comparativo. Educação em Foco, Belo Horizonte, v. 15, n. 19, p. 301-330, jun. 2012.

Felipe Willian Ferreira de Alencar é graduado em Pedagogia pela Escola de Filosofia, Letras e Ciências Humanas da Universidade Federal de São Paulo. Professor da Wish School (SP). ORCID: http://orcid.org/0000-0002-2011-8941

E-mail: f.alencar9@gmail.com 


\section{Editores do volume 9}

José Marcelino de Rezende Pinto - Universidade de São Paulo, São Paulo/SP, Brasil

Nalú Farenzena - Universidade Federal do Rio Grande do Sul, Porto Alegre/RS, Brasil

\section{Comitê Editorial}

José Marcelino de Rezende Pinto - Universidade de São Paulo, Brasil

Juca Gil - Universidade Federal do Rio Grande do Sul, Brasil

Theresa Adrião - Universidade Estadual de Campinas, Brasil Ângelo

Ricardo de Souza - Universidade Federal do Paraná, Brasil

Márcia Aparecida Jacomini - Universidade Federal de São Paulo, Brasil

\section{Conselho Editorial}

\section{Alejandro Morduchowicz}

Universidad Pedagógica, Provincia de Buenos Aires, Argentina

Fernanda Saforcada

Universidade de Buenos Aires, Argentina

Jacques Velloso

Universidade de Brasília, Brasil

João Monlevade

Senado Federal, Brasil

Jorge Abrahão de Castro

Instituto de Pesquisa Econômica Aplicada / IPEA, Brasil

Juca Gil

Universidade Federal do Rio Grande do Sul, Brasil

Lisete Regina Gomes Arelaro

Universidade de São Paulo, Brasil

Luis Carlos Sales

Universidade Federal do Piauí, Brasil

Luiz de Sousa Junior

Universidade Federal da Paraíba, Brasil

Luiz Fernandes Dourado

Universidade Federal de Goiás, Brasil

Magna França

Universidade Federal do Rio Grande do Norte, Brasil

\section{Maria Beatriz Luce}

Universidade Federal do Pampa, Brasil

Universidade Federal do Rio Grande do Sul, Brasil

Marcos Edgar Bassi

Universidade Federal de Santa Catarina, Brasil

\author{
Maria Dilnéia Espíndola Fernandes \\ Universidade Federal de Mato Grosso do Sul, Brasil \\ Nalú Farenzena \\ Universidade Federal do Rio Grande do Sul, Brasil \\ Nelson Cardoso do Amaral \\ Universidade Federal de Goiás, Brasil \\ Nicholas Davies \\ Universidade Federal Fluminense, Brasil \\ Rosana Evangelista Cruz \\ Universidade Federal do Piauí, Brasil \\ Rosana Gemaque \\ Universidade Federal do Pará, Brasil \\ Robert E. Verhine \\ Universidade Federal da Bahia, Brasil \\ Romualdo Portela de Oliveira \\ Universidade de São Paulo, Brasil \\ Theresa Adrião \\ Universidade Estadual de Campinas, Brasil \\ Tristan McCowan \\ University of London, Reino Unido \\ Vera Jacob \\ Universidade Federal do Pará, Brasil \\ Vera Peroni \\ Universidade Federal do Rio Grande do Sul, Brasil \\ Vitor Henrique Paro \\ Universidade de São Paulo, Brasil
}

\section{Equipe editorial}

Apoio ao Comitê Editorial: Patrícia Balthazar Garcia

Diagramação, Revisão de português e normalização: Edson Leonel de Oliveira

Revisão de inglês: Ananyr Porto Fajardo 